\title{
Reliability of Atmospheric Radio Noise Predictions'
}

\author{
John R. Herman
}

\author{
Contribution from AVCO Corporation, Research and Advanced Development Division, Geophysics Section, 201 Lowell Street, \\ Wilmington, Mass.
}

(Received May 15, 1961)

\begin{abstract}
Measured radio noise values are compared with the corresponding International Radio Consultative Committee [C.C.I.R., 1957] predicted values at four noise measuring stations. Five frequencies between 0.013 and $10.0 \mathrm{Mc} / \mathrm{s}$ are considered. The stations selected for this study include Balboa, Panama, near two major radio noise centers, and Byrd Station, Antarctic, remote from atmospheric radio noise sources. It is found that the predicted and measured noise levels are in good agreement except at some places and times, where large discrepancies occur. Most of the disagreements are found at places where the predictions are based on extrapolations of data measured at other stations. Reasons for the disagreements are discussed.
\end{abstract}

\section{Introduction}

Because the success or failure of communications by radio waves depends upon the signal-to-noise ratio at the receiver, it has become necessary to obtain some knowledge of the noise levels to be expected. Atmospherically-generated radio noise levels vary with time of day, season, and geographical location. Prediction of the variations on a worldwide basis have been published in Radio Propagation Unit (R.P.U.) Technical Report No. 5 $[1945,1947]$ and National Bureau of Standards Circular 462 [1948] in terms of the minimum field strengths required to maintain intelligible voice communications ninety percent of the time in the presence of noise. Subsequently, the prediction curves were revised in NBS Circular 557 [Crichlow, $1955]$ to show expected median levels of radio noise power during four-hour time blocks for each season. As more recent data accumulated it became apparent that large discrepancies existed between the measured and predicted values at some locations and times, so that an entirely new set of predictions was prepared and published in International Radio Consultative Committee (C.C.I.R.) Report No. 65 [1957]. The C.C.I.R. predictions closely follow those in Circular 557 , but are based on a wider selection of compatible data, and should thus be more useful than the previous publications.

Cooperative measurements of received noise power at 16 widely separated geographical locations (fig. 1) are currently being conducted on a routine basis under the direction of the National Bureau of Standards Central Radio Propagation Laboratory. Since the issuance of the C.C.I.R. predictions, several additional noise measuring stations have been established and approximately 5 years of data have been collected. Thus it is now possible to check the accuracy of the predictions during a time of declining sunspot activity (1960), and at geographical loca-

1 This work was supported by the U.S. Air Force Cambridge Research Laboratories under Contract No. A F19(604)-4092.

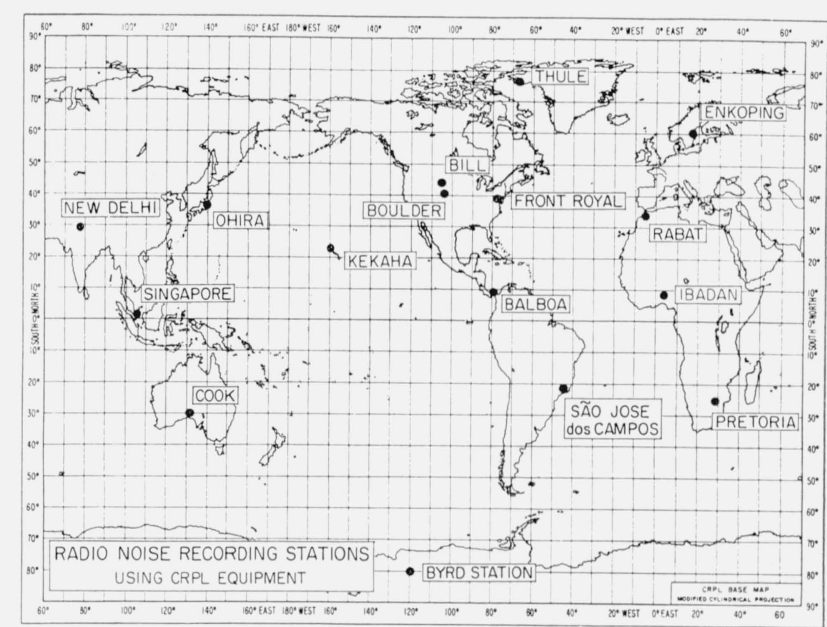

FIGURE 1. Map showing location of noise measuring stations (reproduced from NBS Tech. Note 18).

tions where the noise level could only be interpolated when the predictions were established.

In this paper comparisons are made of the predicted and measured noise values at the four stations listed in table 1 for the frequencies (in $\mathrm{Mc} / \mathrm{s}$ ) shown. The letter $\mathrm{X}$ indicates the frequencies analyzed at each station. These particular stations were selected because their nois a grades range from high to very low. That is, the noise grade at Balboa is high because it is near two major noise centers in Central and South America, while that at Byrd Sta-

TABLE 1

Frequeney $(\mathrm{Mc} / \mathrm{s})$

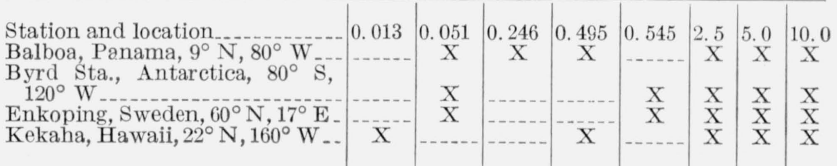


tion is very low because it is remote from all atmospheric noise sources. The noise grades at Kekaha and Enkoping are between these two extremes; that at Kekaha being greater than at Enkoping.

\section{Noise Level Predictions}

The C.C.I.R. predictions are presented as worldwide noise level contour maps for $1.0 \mathrm{Mc} / \mathrm{s}$ in $4-\mathrm{hr}$ time blocks for each season. Curves are given to determine the noise levels at other frequencies between $10 \mathrm{kc} / \mathrm{s}$ and about $30 \mathrm{Mc} / \mathrm{s}$. The magnitude of the noise is in terms of a basic parameter representing the median value of atmospheric noise power passed by a narrow bandwidth, expressed for a 4hour time block. The seasons of the year for the present purpose are defined as in table 2 .

The basic parameter, $F_{a}$ [Crichlow, 1955], used to describe the noise is defined as the noise power available from a short, vertical, grounded, loss-free antenna in decibels above $k T B$, where $k T B$ is the terminal noise power in watts, available from a passive resistance (dummy antenna). Here,

$k=$ Boltzmann's constant $=1.38 \times 10^{-23}$ joules per degree Kelvin.

$T=$ absolute room temperature $=288^{\circ} \mathrm{K}$.

$B=$ effective noise bandwidth in cycles per second $(\mathrm{c} / \mathrm{s})$.

TABle 2. Seasons of the Year (in accordance with C.C.I.R. Report No.65 and NBS Technical Note 18)

\begin{tabular}{|c|c|c|}
\hline \multirow{2}{*}{ Months } & \multicolumn{2}{|c|}{ Season } \\
\hline & $\begin{array}{l}\text { Northern } \\
\text { Hemisphere }\end{array}$ & $\begin{array}{c}\text { Southern } \\
\text { Hemisphere }\end{array}$ \\
\hline $\begin{array}{l}\text { December, January, February } \\
\text { March, April, May, } \\
\text { June, July, August } \\
\text { September, October, November }\end{array}$ & $\begin{array}{l}\text { Winter } \\
\text { Spring } \\
\text { Summer....... } \\
\text { Autumn }\end{array}$ & $\begin{array}{l}\text { Summer. } \\
\text { Autumn. } \\
\text { Winter. } \\
\text { Spring. }\end{array}$ \\
\hline
\end{tabular}

\subsection{Prediction Curves for Each Station}

The expected atmospheric noise level at each of the four noise measuring stations listed in table 1 are shown in figures 2 to 5 by solid lines for each season of the year and each frequency. The corresponding measured noise values are shown in the figures by dashed lines, and the estimated manmade noise levels at the stations are depicted as broken lines. (All times referred to in this paper are local times.) More about the measured values is given in the next section.

The expected atmospheric noise levels shown in figures 2 to 5 were prepared from the noise grade maps given in the C.C.I.R. report. Because the noise maps are for $1.0 \mathrm{Mc} / \mathrm{s}$ only, the predicted values of $F_{a}$ for the frequencies considered here were extrapolated using the curves of noise power as a function of frequency given in figures 21 and 22 of that report. In a few cases, notably at Marie Byrd Station and at Kekaha for some time blocks, the interpolation between noise isopleths on the maps is rather broad, but the chosen values should be correct within one or $2 \mathrm{db}$.
The estimated manmade noise levels shown in figures 2 to 5 were also obtained from the C.C.I.R. report. The values represent what should be expected at receiving sites located several miles from populated areas and at least a quarter of a mile from elevated power lines and electrical machinery.

\section{Noise Level Measurements}

\subsection{Seasonal Time-Block Measured Values}

The noise power is recorded for $15 \mathrm{~min}$ per $\mathrm{hr}$ for each frequency, and each sampling is assumed to represent the noise level for the full hour. From these data the month-hour medians, $F_{a m}$, are obtained in terms of decibels above $k T B$ and are compiled in the NBS Technical Note 18 Series [Crichlow, $1959 \mathrm{a}$ and b]. Also given are the seasonal 4-hr time block values, averaged over each 4-hr period for the 3 months of the season in accordance with C.C.I.R. recommendations. The tabulations include the upper and lower decile values of $F_{a}$ to give an indication of the extent of the day to day variations from the median, $F_{a m}$. The appropriate seasonal timeblock noise power averages as reported by Crichlow [1959b] are plotted as dashed lines in figures 2 to 5 .

Since the noise-measuring equipment approximates, insofar as practicable, the idealization of the system for which the predictions were generated, and corrections have been made in the measured data for antenna losses and the like, the measured and predicted values of noise power given in figures 2 to 5 can be compared directly.

\subsection{Comparison of Measured and Predicted Sea- sonal Time-Block Values}

As is evident from the curves of figures 2 to 5 , a great number of discrepancies exist between the predicted and measured values of noise power. In several cases there is very good agreement, but in others the predicted noise level is as much as $40 \mathrm{db}$ lower or $24 \mathrm{db}$ higher than that actually measured. However, it should be noted that in most of the disagreements the predicted noise level is on the low side, and a predicted value $24 \mathrm{db}$ too high occurs only once (winter 1600-2000 hour time block at Byrd Station on $0.051 \mathrm{Mc} / \mathrm{s}$ ) in the data analyzed here. Furthermore, most of the too-high predicted values occur at Byrd Station and Enkoping, where the prediction curves are based on scanty data or extrapolation techniques.

Measured values that are much higher than the corresponding predicted values can be attributed to a number of causes. One of the most important causes is manmade noise near the receiving station. This can arise from automobile ignition systems, power lines, and electrical machinery, which is propagated primarily over power lines or by ground waves. Since manmade noise is random it is present on all the measured frequencies. Another important contribution to the measured noise level might arise from local station interference, and this would show up on only one frequency. Atmospherics generated by local thunderstorm activity would 

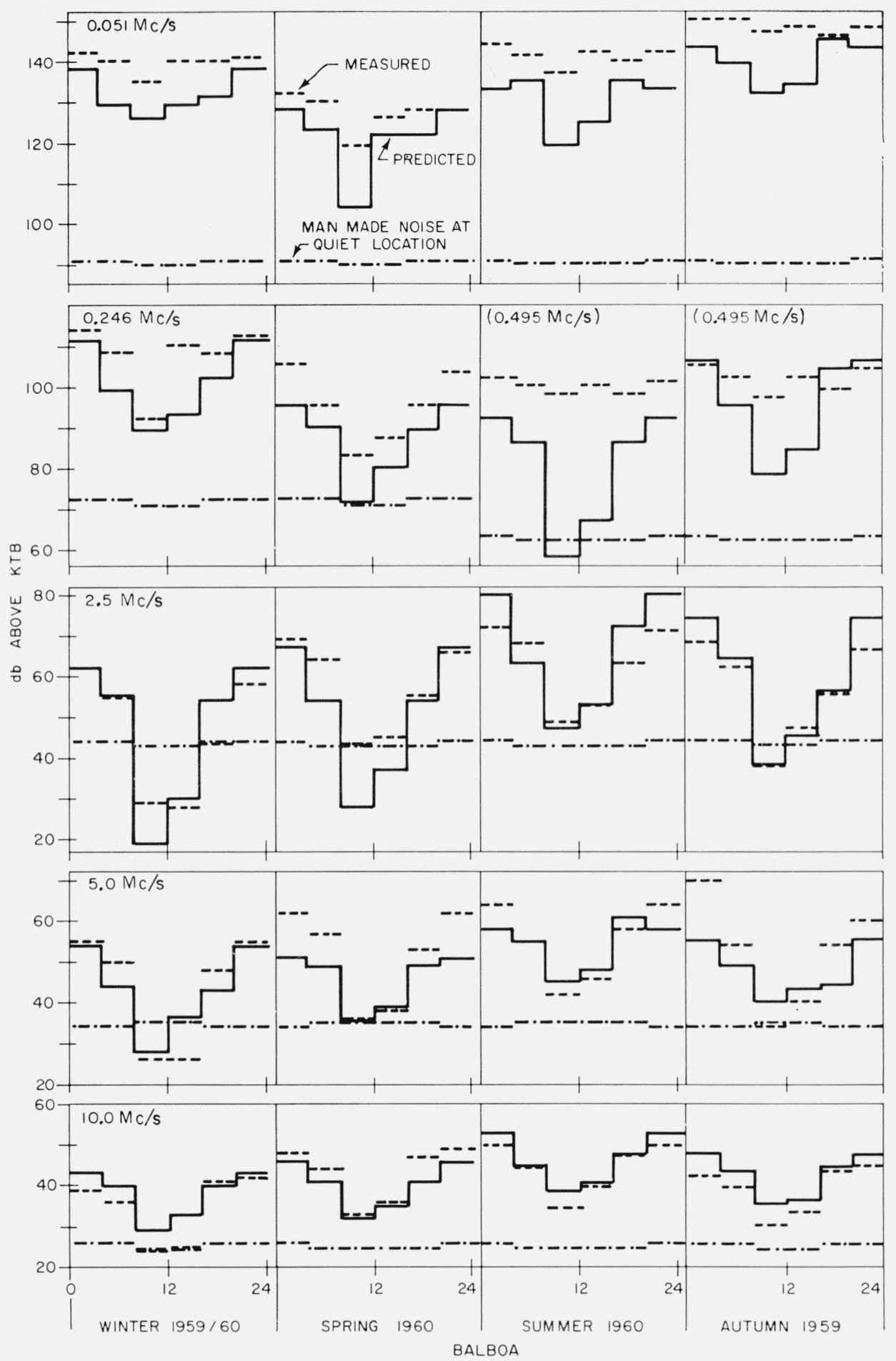

Figure 2. Predicted and measured noise power at Balboa, Panama. Prediction curves scaled from C.C.I.R. Report No. 65. 


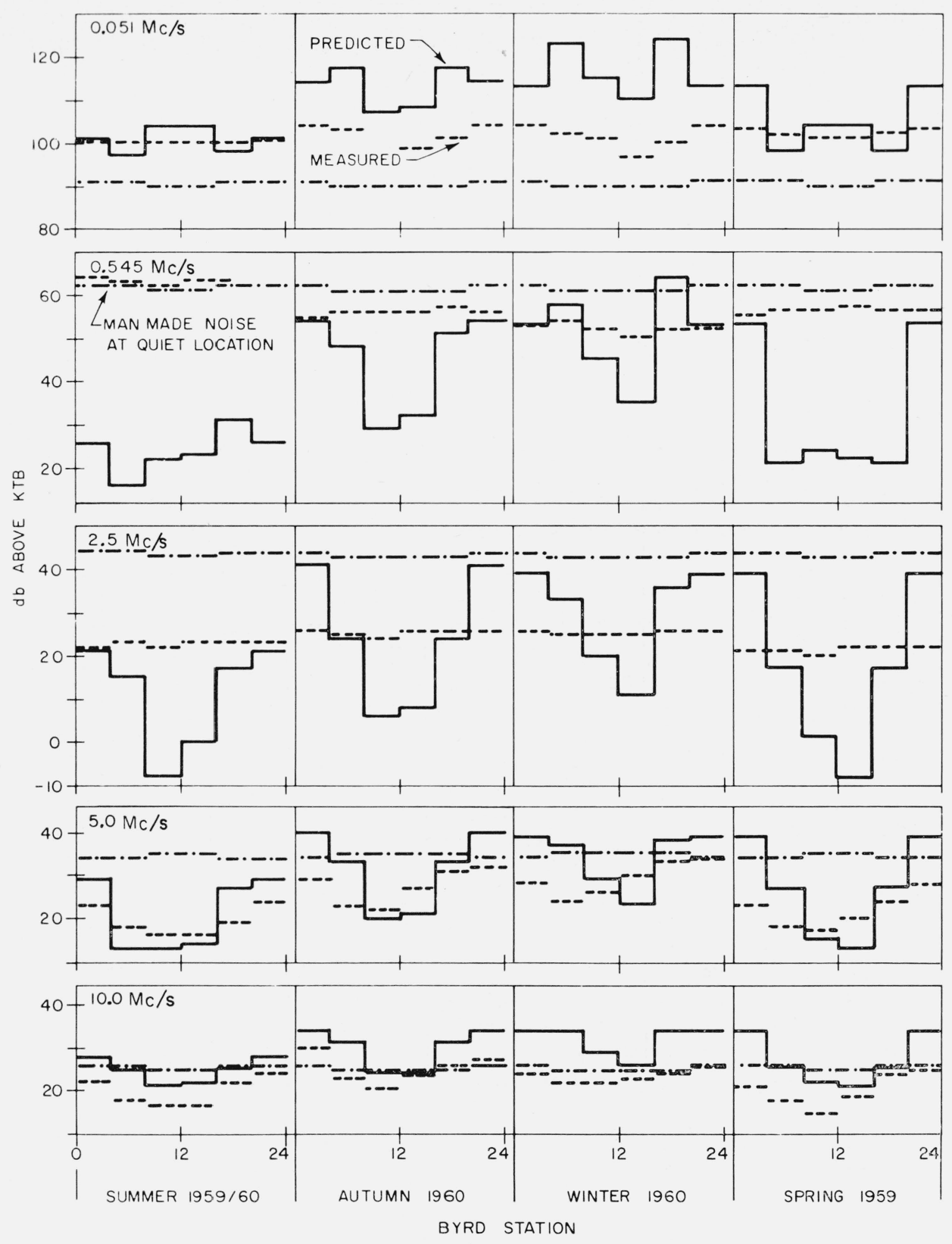

Figure 3. Predicted and measured noise power at Byrd Station, Antarctica. Prediction curves scaled from C.C.I.R. Report No. 65.

greatly increase the received noise power, but this has been taken into account in the prediction curves from a knowledge of worldwide thunderstorm activity. Thus, unless the locale of a receiving station suffered a higher-than-usual number of thunderstorms spaced over a 3-month period, local atmospheric noise would not be the cause of a measured noise value much higher than that predicted in a seasonal time block.

The prediction curves were issued for atmospheric noise levels primarily, while the noise data [Crichlow, $1959 \mathrm{a}$ and $\mathrm{b}]$ include radio noise of all types; man- made, cosmic, and atmospheric; which happened to be incident on the antenna at the time of measurement. Data which obviously contained manmade noise, interfering signals or equipment trouble have been omitted from the compilations, but these effects have not been eliminated in all cases [Crichlow, 1959 b]. Thus, the high noise level measured at Balboa on $0.495 \mathrm{Mc} / \mathrm{s}$ in the spring and summer (fig. 2) probably contains a strong contribution from a local interfering signal. Were it manmade noise or local atmospherics, the corresponding data on $2.5,5.0$, and $10.0 \mathrm{Mc} / \mathrm{s}$ would show its effects. The higher-than-predicted 


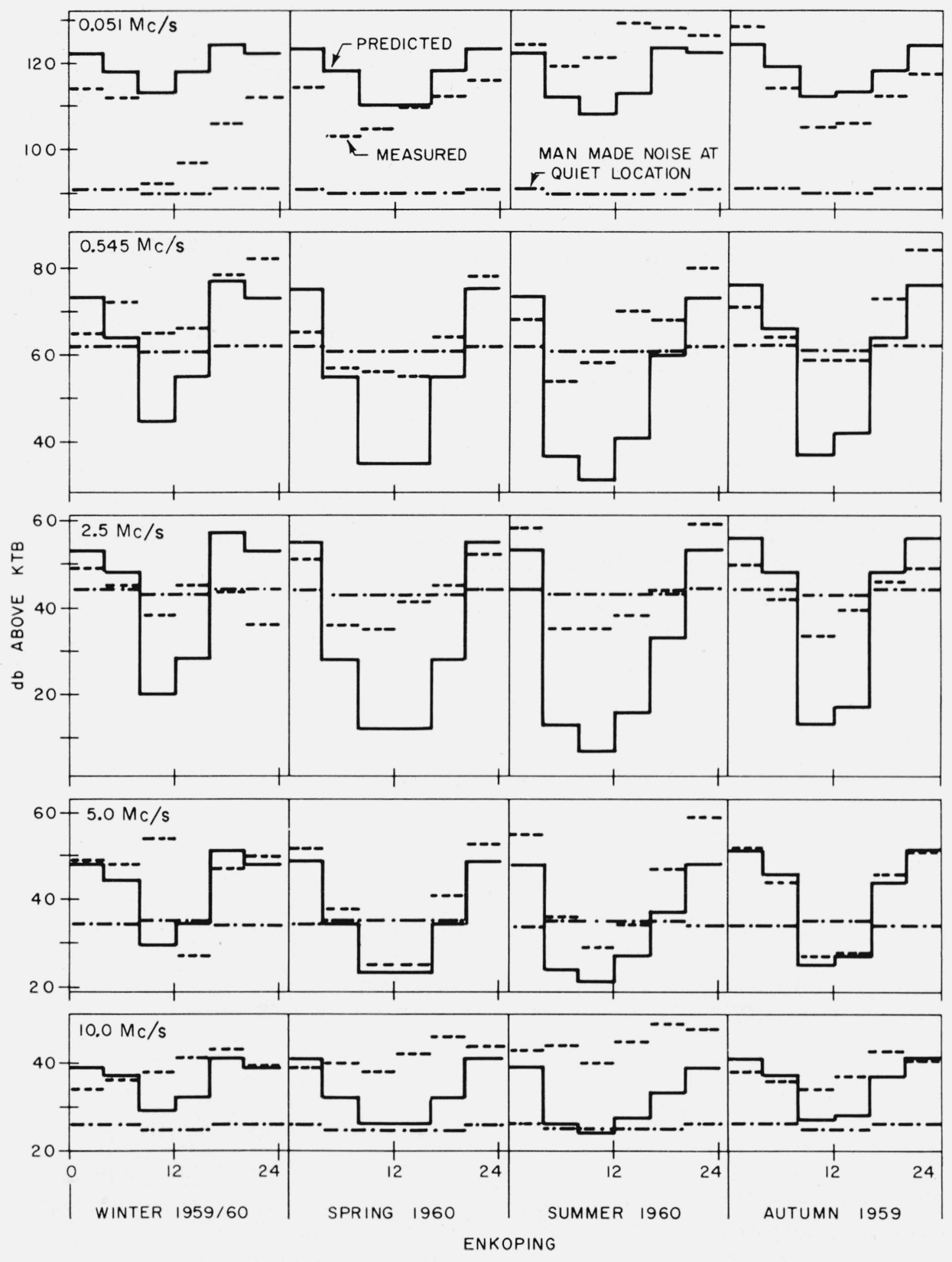

Figure 4. Predicted and measured noise power at Enkoping, Sweden.

Prediction curves scaled from C.C.I.R. Report No. 65.

noise values measured at Balboa on $5.0 \mathrm{Mc} / \mathrm{s}$ during the night hours (2000-0400) of spring, summer, and autumn also apparently contain an interfering signal. In this case, however, the signal appears to have been ionospherically propagated from a distant transmitter, because it disappears during the daytime when ionospheric absorption is effective.

The data from Byrd Station (fig. 3) are of particular interest because this station is located in a very low noise region where no previous noise measurments had ever been made. The C.C.I.R. report suggests caution in the use of predicted values which fall below the estimated manmade noise levels for a quiet receiving site, and this is just the case for the frequencies of $0.545,2.5$, and $5.0 \mathrm{Mc} / \mathrm{s}$ at Byrd Station. Since thunderstorm activity is practically nonexistant at Byrd Station, the atmospheric radio noise must be propagated in from distant sources, such as the major noise centers in equatorial Africa, South America, and the East Indies. Other contributions to the measured noise level would, of course, arise from local manmade sources and interfering 

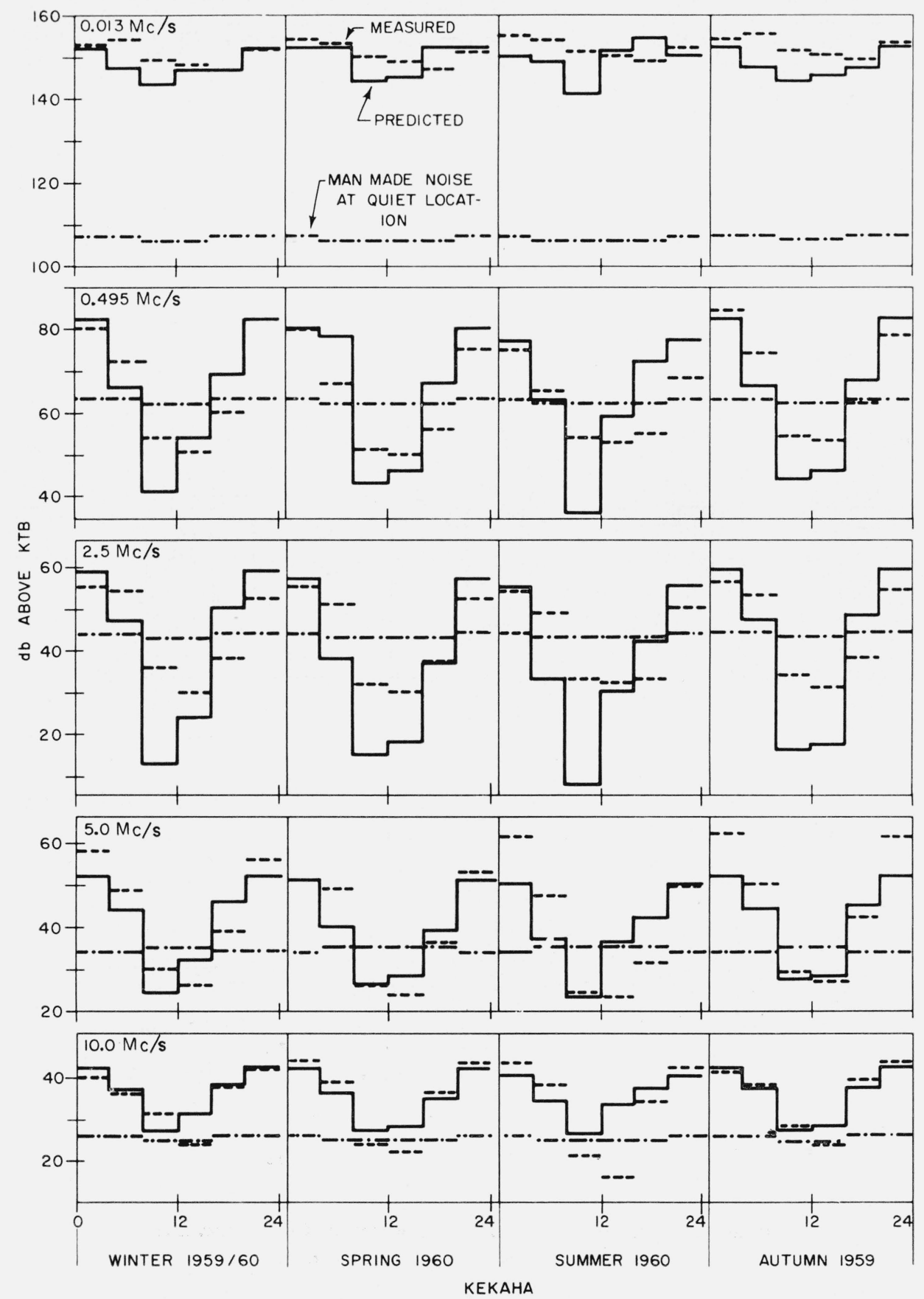

Figure 5. Predicted and measured noise power at Kekaha, Hawaii. Prediction curves scaled from C.C.I.R. Report No. 65

signals. In addition, as pointed out by Crichlow [1959 a], the methods used for determining antenna losses at Byrd have not been completely accurate, so this may contribute to the observed discrepancies between the predicted and measured noise values in figure 3. At times during winter a large amount of precipitation noise can be generated at the receiving antenna by snow being blown against the antenna.
Two additional noise sources may be of importance in polar regions, such as at Byrd Station. The first consists of aurorally generated noise which at times can be as much as $15 \mathrm{db}$ above atmospheric noise on $18 \mathrm{Mc} / \mathrm{s}$ [Egan and Peterson, 1960] and significantly greater than atmospheric noise on $5 \mathrm{kc} / \mathrm{s}$ [Ellis, 1959]. The second, of importance on frequencies above about $2 \mathrm{Mc} / \mathrm{s}$, is cosmic noise which can penetrate 
the ionosphere near the poles where the critical frequency is low in winter, suffer ground reflection, and subsequently be propagated below the ionosphere by conventional means [Ellis, 1958].

To some extent the various types of noise sources which contribute to the measured values can be identified. For example, the presence of ionospherically propagated atmospheric noise in the Byrd Station data is indicated by the following two facts:

(1) A small seasonal variation can be seen (fig. 3) in the measured data on 0.051 and $0.545 \mathrm{Mc} / \mathrm{s}$, where the minimum occurs during winter. This minimum probably corresponds to the absence of the $D$ and $E$ reflecting layers during the sunless Antarctic winter.

(2) The noise levels are generally higher in winter on the 5.0 and $10.0 \mathrm{Mc} / \mathrm{s}$ frequencies, complementing the behavior of the low frequencies in fact (1). That is, propagation of the high frequencies is expected to be better in winter because of the absence of the $D$ region which is an absorber for these frequencies.

In considering the data for 0.051 and $0.545 \mathrm{Mc} / \mathrm{s}$ alone, one might be tempted to infer a predominance of manmade noise, where the seasonal minimum coincides with the relative inactivity of the station during winter. However, if this were true the noise level of the high frequencies would also be less during winter. On the other hand, that there is substantial manmade noise present is evidenced by an almost complete lack of seasonal and diurnal variation in the $2.5 \mathrm{Mc} / \mathrm{s}$ data. It should be noted that the measured values for this frequency fall about $20 \mathrm{db}$ below the estimated level of manmade noise.

The measured noise values at Enkoping (fig. 4) on 0.545 and $2.5 \mathrm{Mc} / \mathrm{s}$ are substantially higher than predicted for all seasons during the daytime, which would indicate either a large contribution from manmade noise or interference, or an error of 20 to $30 \mathrm{db}$ in the prediction. On $0.051 \mathrm{Mc} / \mathrm{s}$ the predicted values for the winter afternoon and evening time blocks are 21 and $18 \mathrm{db}$ too high, respectively, and for the same time blocks during summer the predicted values are 16 and $5 \mathrm{db}$ too low.

In figure 5 it can be seen that generally good agreement obtains between the predicted and measured noise values at Kekaha, Hawaii. During the day on $2.5 \mathrm{Mc} / \mathrm{s}$ the predicted noise level is on the order of $20 \mathrm{db}$ below the measured level, but both are below the estimated manmade level and must be viewed with reservation. The higher-thanexpected values measured on $5.0 \mathrm{Mc} / \mathrm{s}$ at Kekaha probably contain a large amount of station interference, as suggested by Crichlow [1959 a].

\subsection{Month-Hour Median Measured Values}

As an illustration of the diurnal noise patterns occurring seasonally in various parts of the world, month-hour medians of $F a$ measured on $5.0 \mathrm{Mc} / \mathrm{s}$ are plotted in figure 6 for selected months. The upper decile curves shown in this figure represent the noise value exceeded 10 percent of the time, while the lower decile value was exceeded 90 percent of the time.
Comparison of the month-hour median curves in figure 6 with the corresponding time-block curves in figures 2 to 5 reveal variations in the median of only 2 or $3 \mathrm{db}$ within a 4 -hr time block, except during: sunrise and sunset periods. Month-hour median plots for the other frequencies compare similarly. With this in mind, the diurnal features of the different frequencies can be discussed on the basis of the curves in figures 2 to 5 .

As expected, the diurnal variation of the frequencies at $0.495 \mathrm{Mc} / \mathrm{s}$ and higher show the effect of daytime ionospheric absorption, while the lower frequencies at 0.013 and $0.051 \mathrm{Mc} / \mathrm{s}$ exhibit little daily variation. The situation at Byrd Station, and to a lesser extent at Enkoping, is somewhat different. Smaller diurnal variations occur during summer and winter on the higher frequencies because the long periods of daylight during summer allows absorption $24 \mathrm{hr}$ a day, which is completely absent during the sunless winter. The days of the transition seasons, fall and spring, have hours of daylight as well as darkness, so the diurnal variation at Byrd Station during these months is greater.

At the equator the times of sunrise and sunset do not change with season, so that the spread of the measured noise value in the $0400-0800$ and $1600-$ 2000-hr time blocks should be about the same all year. At Kekaha $\left(22^{\circ} \mathrm{N}\right)$ the sun rises at about 0530 in summer and at about 0630 in winter, so this difference is not too important. However, at Enkoping $\left(60^{\circ} \mathrm{N}\right)$ the sun rises at 0300 in summer (June) and not until 0900 in winter (December).

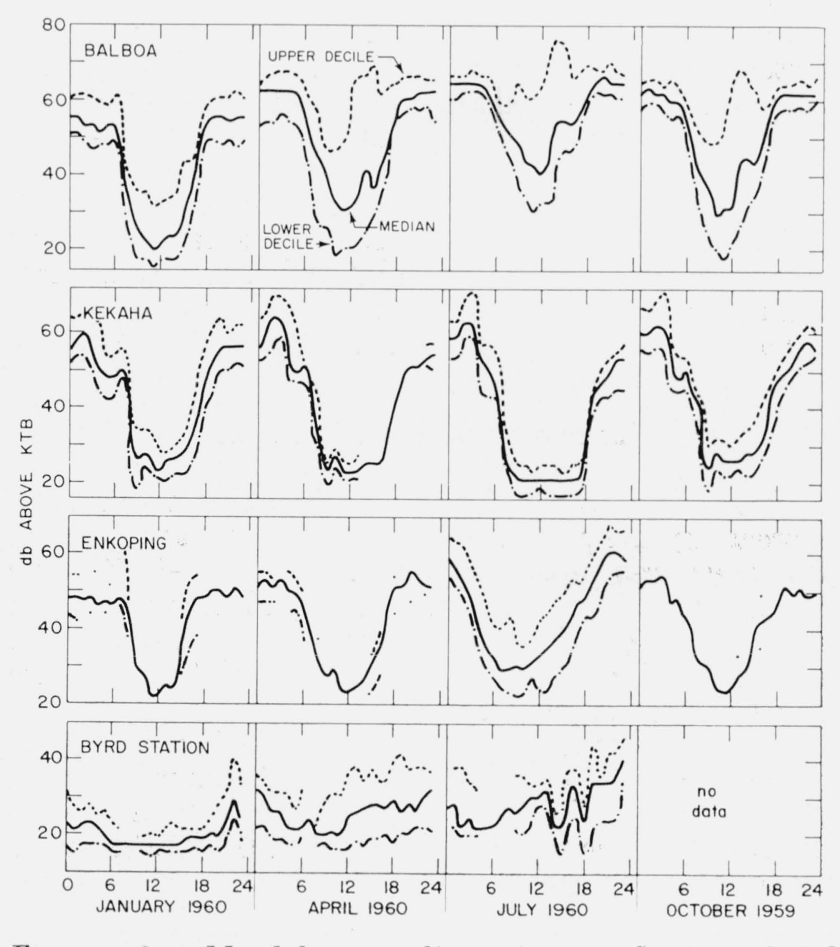

Figure 6. Month-hour medians (measured) for selected months on $5.0 \mathrm{Mc} / \mathrm{s}$. 
Thus, during summer at Enkoping large variations occur in the 0000-0400 hour time block (fig. 6), but during winter the variations due to sunrise conditions occur in the 0800-1200-hr time block. From this it is evident that the predicted values for time blocks containing sunrise and sunset can give only a rough indication of the median noise to be expected over the entire periods, and are less representative for individual hours than those for other time blocks.

\subsection{Measured Variations in Medians}

Within a 4-hr time block large day-to-day variations from the median are observed in the measured noise power. The noise power variations are expressed in terms of the ratio (in $\mathrm{db}$ ) of upper decile to median, $\mathrm{D}_{u}$, and lower decile to median, $\mathrm{D}_{l}$, and are tabulated by Crichlow [1959 b] along with the monthly median values. An attempt was made in the C.C.I.R. report to predict the magnitude of $\mathrm{D}_{u}$ and $\mathrm{D}_{l}$ in each $4-\mathrm{hr}$ time block as a function of frequency, but without regard to season or geographical location.

Thus, to compare the measured and predicted values of $D_{u}$ and $D_{l}$ the measured data were averaged over a 1-yr period (September 1959 to August 1960) in each 4-hr time block. For illustration, the average variations measured in the 1200-1600-hr time block at each of the 4 stations on the different frequencies are plotted in figure 7 as a function of frequency. The predicted values of $D_{u}$ and $D_{l}$ as a function of frequency for the same time block are shown as solid curves.

In figure 7 it can be seen that the measured variations are as much as $13 \mathrm{db}$ greater than predicted (as at Balboa on $2.5 \mathrm{Mc} / \mathrm{s}$ ) or $13 \mathrm{db}$ less than predicted (as at Byrd Station on $0.545 \mathrm{Mc} / \mathrm{s}$ ). At Kekaha, the predicted and measured values of $D_{u}$ and $D_{l}$ are generally in good agreement. Differences between the predicted and measured values of $D_{u}$ and $D_{l}$ for individual months are greater than $13 \mathrm{db}$ in some cases. Generally, it can be said that the measured variations at high latitude stations are less than predicted while those at stations near the equator are greater than predicted.

\subsection{Noise Power as Function of Frequency}

Figure 8 shows the decrease in noise power with increasing frequency. The plotted points represent the measured noise power in the 0000-0400 time block averaged over $1 \mathrm{yr}$. The solid curve for each station was obtained from figure 22 in the C.C.I.R. report and indicates the expected variation of noise power with frequency.

The measured noise power variation with frequency as shown in figure 8 corresponds rather well with that predicted at all stations. The largest discrepancy occurs at Balboa on $0.013 \mathrm{Mc} / \mathrm{s}$, where the measured value is about $17 \mathrm{db}$ higher than that

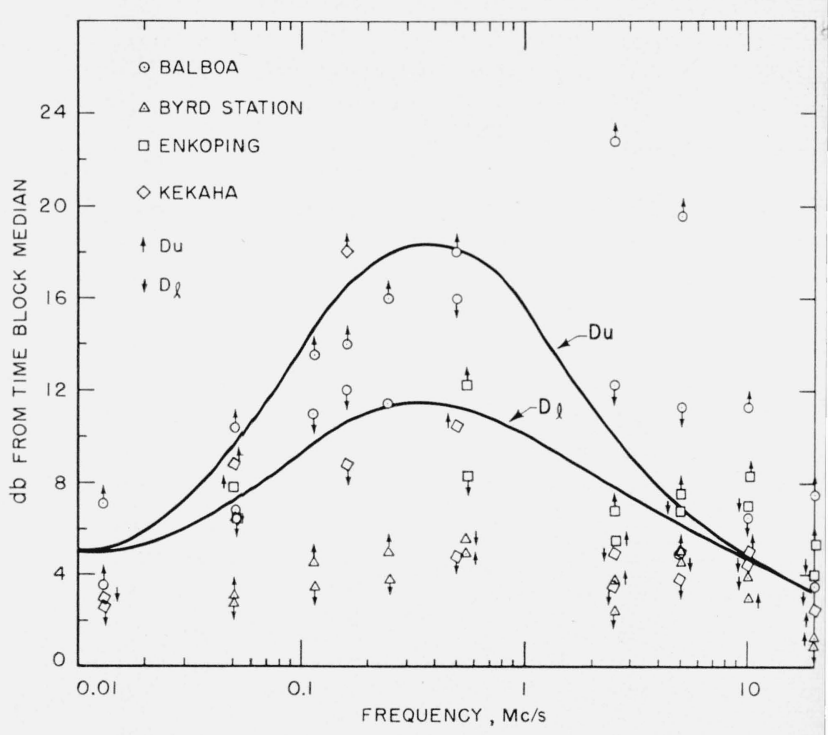

Figure 7. Variations from time block median radio noise levels.

Solid curves $\mathrm{Du}$ and $\mathrm{D}_{l}$ are upper and lower deciles predicted by C.C.I.R. Report No. 65 , figure 25 .

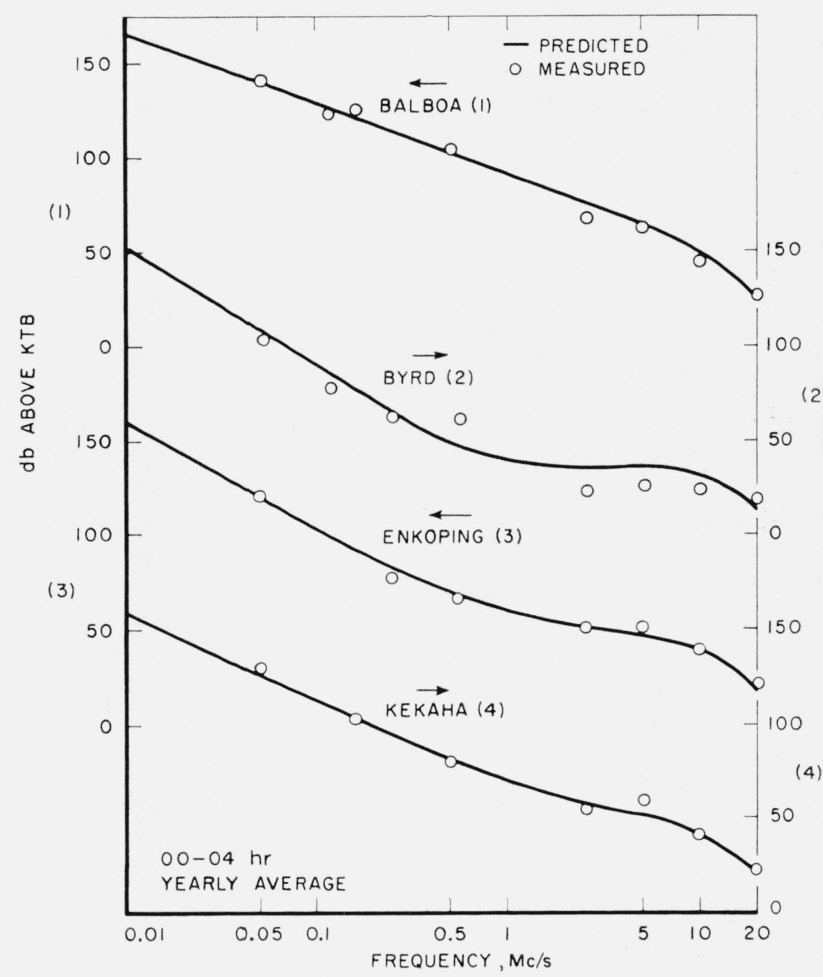

Figure 8. Noise power as a function of frequency.

Plotted points are one year average of measured noise power in 0000-0400 time block. Solid curves are taken from C.C.I.R. Report No. 65, figure 22 .

predicted. Discrepancies greater than $10 \mathrm{db}$ occur in only 10 percent of the measured points in figure 8 . However, during individual months greater de- 
partures appear, which should be taken into account in any future prediction curves. The good agreenent between predicted and measured values in figure 8 indicates that the measured data considered here primarily represent noise of atmospheric origin.

\subsection{Ratio of Measured to Predicted Values}

The percentage distribution of the deviations of predicted from measured values are shown in figures $9 \mathrm{a}$ and $9 \mathrm{~b}$. The ratios of measured to predicted values are divided into the class intervals \pm 0 to 10 $\mathrm{db}, \pm 10$ to $20 \mathrm{db}$, and $\pm 20 \mathrm{db}$ or greater. The percentage distributions are shown in two ways. In figure $9 \mathrm{a}$, the observed deviations for 1 yr counted on all frequencies at each station are given to illusrate the reliability of the predictions at different ocations. In figure 9b, the observed deviations for the same year counted at all stations on each frequency are given to illustrate the reliability of the oredictions for different frequencies.

From the percentage distributions of the ratios of observed to predicted noise levels given in figure 9a, it appears that the predictions are most reliable at Kekaha and Balboa, where over 80 percent of the observed deviations are $10 \mathrm{db}$ or less. At Enkoping and Byrd Station less than 70 percent of the observed deviations are $10 \mathrm{db}$ or less. At Byrd Station, 18.4 percent of the observed deviations were greater than $\pm 20 \mathrm{db}$, and nearly all of the observations were on the plus side. This strongly suggests local interference, which also adversely affects the percentage distribution of $0.545 \mathrm{Mc} / \mathrm{s}$ given in figure $9 \mathrm{~b}$.

The percentage distributions given in figure $9 \mathrm{~b}$ indicate that the predictions are most reliable for 0.013 and $10.0 \mathrm{Mc} / \mathrm{s}$, where 100 and 90 percent of the observed deviations were $10 \mathrm{db}$ or less, respectively. The large percentage of deviations greater than 20 $\mathrm{db}(33 \%)$ observed on $0.545 \mathrm{Mc} / \mathrm{s}$ is due to the Byrd Station data. With those data excluded, the percentage deviation of the three class intervals for $0.545 \mathrm{Mc} / \mathrm{s}$ become 63,21 , and 16 percent, respectively.

The distributions for 2.5 and $5.0 \mathrm{Mc} / \mathrm{s}$ can be compared with a similar reliability test of the revised R.P.U. predictions as reported in Circular 462 (NBS, 1948). The comparison is not strict, however, due o the difference in sampling used here. The present distributions are based on the measurements of four stations, while those in Circular 462 were based on 17 stations. Thus, it is not unexpected that the reliability indicated in figure $9 \mathrm{~b}$ on both frequencies is ess than in Circular 462, where the percentage of observations for the three $10 \mathrm{db}$ class intervals ( 0 to $30 \mathrm{db}$ ) were: 75,20 , and 5 percent for $2.5 \mathrm{Mc} / \mathrm{s}$; and 90,8 , and 2 percent for $5.0 \mathrm{Mc} / \mathrm{s}$.

\section{Summary}

Although good agreement is generally found between the predicted and measured noise power values, large differences still exist at some places and times. At places such as Kekaha, where the predic-

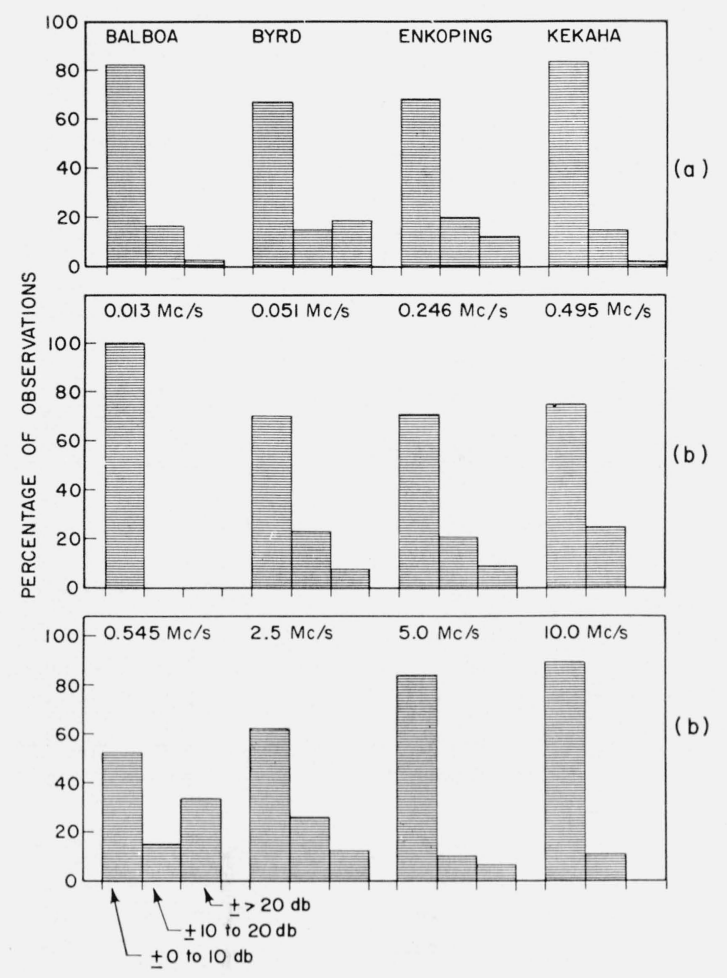

Figure 9. Percentage of observed deviations: (a) on all frequencies at each station, and (b) at all stations on each frequency.

tions are based on previous noise measurements, the differences are small, but at locations where the predictions are based on interpolated or extrapolated data (as at Byrd Station), large differences occur. The differences between predicted and measured values range from +40 to $-24 \mathrm{db}$.

In time blocks containing sunrise or sunset, the predicted values give only an indication of the median noise power to be expected over the entire periods and are less representative of individual hours than those for other time blocks.

The measured variations from the median, averaged over a 1 year period, differ from the predicted variations by as much as $\pm 13 \mathrm{db}$. In individual months larger discrepancies than this occur.

The noise power data considered in this paper follow the expected frequency dependence very well. Discrepancies greater than $10 \mathrm{db}$ occur in only 10 percent of the cases, and the greatest departure is 17 $\mathrm{db}$ at Balboa on $0.013 \mathrm{Mc} / \mathrm{s}$.

Of four stations investigated, it appears that the C.C.I.R. predictions are most reliable for Kekaha and Balboa, where over 80 percent of the ratio of measured to predicted values were $10 \mathrm{db}$ or less, while less than 70 percent of the observations at Enkoping and Byrd Station were in this class. In comparing the predicted to measured values as a function of frequency, it was found that the ratio was $10 \mathrm{db}$ or less in 100 and 90 percent of the observations for 0.013 and $10.0 \mathrm{Mc} / \mathrm{s}$, respectively. 
The author thanks R. Penndorf, S. C. Coroniti, and G. E. Hill for their critical reading of the manuscript and helpful suggestions, and Mrs. Carolyn Kotce for her tireless efforts in preparing the prediction curves for each station.

NoтE: Another interpretation of the discrepancies with the C.C.I.R. predictions will appear in a later issue of this journal under the authorship of W. Q. Crichlow and R. T. Disney of the Central Radio Propagation Laboratory, National Bureau of Standards. (Editor)

\section{References}

C.C.I.R. Report No. 65, Revision of atmospheric radio noise data, Internationa! Telecommunication Union, Geneva (1957).

Crichlow, W. Q., D. F. Smith, R. N. Morton, and W. R. Corliss, World-wide radio noise levels expected in the frequency band from 10 kilocycles to 100 megacycles, U.S. Dept. of Commerce, NBS Circ. 557 (Aug. 1955).
Crichlow, W. Q., C. A. Samson, R. T. Disney, and M. A. Jenkins, Radio noise data for the International Geophysical Year July 1, 1957-December 31, 1958, U.S. Dept. o Commerce, NBS Tech. Note 18 (July 27, 1959a).

Crichlow, W. Q., C. A. Samson, R. T. Disney, and M. A. Jenkins, Quarterly radio noise data, U.S. Dept. of Com merce, NBS Tech. Note 18 Series (1959b).

Egan, R. D., and A. M. Peterson, Auroral noise at HF. J. Geophys. Research 65, 3830 (1960).

Ellis, G. R. A., The trapping of cosmic radio waves beneath the ionosphere, J. Atmospheric and Terrest. Phys. 13, 61 (1958)

Ellis, G. R. A., Low frequency electromagnetic radiation associated with magnetic disturbances, Planetary and Space Science 1, No. 4, 253 (1959).

National Bureau of Standards Circ. 462, Ionospheric radic propagation, U.S. Dept. of Commerce (1948).

Radio Propagation Unit Technical Report 5 (1st ed.), Mini mum required field intensities for intelligible reception of radio telephony in presence of atmospherics or receiving set noise, Holabird Signal Depot, Baltimore, Md. (Dec. 1945); R.P.U. Technical Report 140 (revised ed., July 1947).

(Paper 65D6-160) 